\title{
A QUESTÃO DA SUBJETIVIDADE NA POESIA DE HERBERTO HELDER: O RETRATO EM MOVIMENTO NO PAPEL
}

\author{
Tatiana Aparecida Picosque ${ }^{1}$
}

RESUMO: Na obra de Herberto Helder, encontramos a concepção de uma subjetividade em devir, já que o eu poético está sempre a narrar o seu processo de transmutação em virtude do processo criativo. Portanto, a concepção de subjetividade que dela se extrai não coincide com a de um sujeito que se pretenda coerente e determinado, ou seja, dotado de uma identidade fixa. E no intuito de discorrer sobre esta subjetividade incessantemente transmutada pela experiência poética, propomos então a análise de Retratíssimo ou narração de um homem depois de maio, poema do início da carreira do escritor e que já nos aponta para a impossibilidade de pensarmos a questão da subjetividade em moldes tradicionais.

PALAVRAS-CHAVE: Herberto Helder; subjetividade; devir; processo criativo.

RÉSUMÉ: Chez Herberto Helder, nous trouvons la conception de la subjectivité en devenir, puisque le je poétique ne cesse de dire son processus d'ouverture en vertu du processus de création. Par conséquent, la conception de la subjectivité ne correspond pas au sujet qui doit être déterminé et cohérent, c'est à dire doué d'une identité fixe. Et afin de discuter de cette subjectivité modifiée par l'expérience poétique, nous proposons l'analyse de Retratíssimo ou narração de um bomem depois de maio, poème du début de carrière de l'écrivain et qui déjà souligne l'impossibilité de la subjectivité pensée d'une manière traditionnelle.

MOTS-CLÉS: Herberto Helder; subjectivité; devenir; processus de création.

Porque en sou uma abertura Herb erto Helder

A obra de Herberto Helder (1930-) constitui referência incontornável aos leitores de poesia portuguesa contemporânea e de poesia em geral. Dono de uma vasta produção que se inicia no final da década de 50 , constata-se que a sua obra de modo incessante se transmuta e que, incrivelmente, consegue tornar-se a cada renovação ainda mais multifacetada e, por isso, ainda mais complexa. O leitor que o lê devagar percebe que, na verdade, o autor intenta engendrar uma genuína máquina poética de perguntas e não de respostas prontas ao leitor. A eficiência da obra herbertiana consiste no fato de sempre colocar em xeque quaisquer conhecimentos assentados, procurando assim galvanizar tanto o corpo do autor quanto o do leitor com o poema.

\footnotetext{
${ }^{1}$ Doutoranda do Programa de Pós-Graduação em Literatura Portuguesa (USP). Bolsista da FAPESP.
} 
Se, por um lado, a obra de Herberto Helder é extensa, por outro, Herberto Helder, o autor empírico, praticamente não existe. Quem o lê e se interessa pelas escassas informações de ordem biográfica a seu respeito sabe que o poeta não aceita prêmios relevantes em dinheiro, que não concede entrevistas no intuito de situar a intencionalidade de sua obra, que não frequenta eventos literários, entre outras atitudes esperadas de um autor de obra relevante.

Astutamente, Herberto Helder afasta-se da vida pública e deixa o leitor à mercê do que lhe interessa: a experiência da leitura da obra a partir da própria obra. Na realidade, uma das grandes estratégias de Herberto Helder parece ser a de evitar a leitura de seus poemas com respaldo no autor empírico, o que implicaria o risco de vincular a sua obra a uma subjetividade pensada em moldes tradicionais. Quando se procura pelo autor empírico com o objetivo de "explicar" a intencionalidade da obra, na verdade, quase sempre o que se procura é o retrato claro e exterior de um "sujeito", enquanto uma unidade subjetiva por detrás da obra e que a justificaria ou a fundaria.

Retirando-se então o autor da cena pública, temos que a sua obra impossibilita ou dificulta ao leitor a ingênua correspondência entre o autor empírico e o eu poético, evitando assim a concepção de um autor enquanto fundador coerente da obra e que ensejaria, por esta razão, o seu pleno conhecimento. E além deste "desaparecimento empírico", constatamos que em muitos de seus poemas o próprio eu poético - ou a voz do poeta - chega mesmo a desaparecer, lembrando a asserção mallarmeana oitocentista que anunciava o "desaparecimento elocutório do poeta" em prol da "iniciativa às palavras" (MALLARMÉ, 2008, p. 158).

A título de exemplo, citemos um poema do livro $A$ faca não corta o fogo em que esta iniciativa às palavras torna-se mais reconhecível:

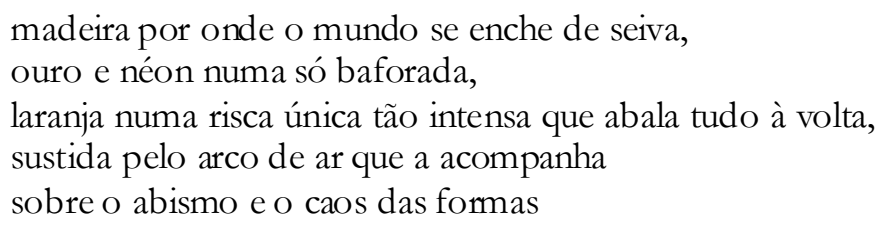

(HELDER, 2009, p. 558)

No poema em questão, o eu poético não tem lugar, uma vez que a necessidade de conferir a iniciativa às palavras parece destiná-lo a uma espécie de anonimato, confeccionando-se assim um poema cujo protagonista é a natureza. Mas nem sempre é 
deste modo, e a obra herbertiana acaba também abarcando o eu poético em inúmeros de seus poemas, o que nos permite discutir a questão da subjetividade em seu âmbito. Mesmo porque em literatura a questão da simples correspondência entre sujeito empírico e sujeito textual parece-nos hoje um problema menor entre os leitores especializados. Mais urgente, a nosso ver, torna-se inquirir sobre a espécie de subjetividade que aparece articulada em obras de autores contemporâneos, como é o caso de Herberto Helder.

Sobre o problema da subjetividade, estejamos cientes de que arte e filosofia vêm repensando-a, procurando, sobretudo, afastá-la do modo clássico de conceituá-la. Na filosofia do século XIX, Friedrich Nietzsche já empreende a tarefa de refutar o sujeito de feitio cartesiano. No século XX, pensadores como Gilles Deleuze, Maurice Merleau-Ponty, Michel Foucault, entre outros, formulam outro conceito de subjetividade, mais aberto, mais alargado, mais atrelado ao corpo e que, por seu turno, contrapõe-se ao sujeito anteriormente concebido de modo uno, coerente, fixo e, o que é mais grave, concebido enquanto fundamento seguro do conhecimento.

Michel Foucault afirma que os discursos providos do que ele denomina funçãoautor acabam abarcando, na realidade, uma "pluralidade de eus". Tais discursos, providos da função-autor, podem “dar lugar a vários 'eus', em simultâneo...” (FOUCAULT, 1997, p. 45). O pensador deseja minar, assim, o efeito da voz discursiva coerente e unitária. Examinando a função-autor, Michel Foucault acaba reexaminando a questão da subjetividade, passando a analisar o processo de sua construção no plano do discurso, do texto em geral. Salientemos: agora se trata da subjetividade construída no âmbito do texto.

Com a obra de Herberto Helder não poderia ser diferente e, por isso, o poeta também recusa terminantemente o modelo de subjetividade herdado das filosofias da consciência, problematizando-a e propondo-nos outra concepção de subjetividade: aquela cuja construção se efetiva no papel, por meio da obra, e que parece mais em sintonia com o pensamento contemporâneo.

Sendo assim, podemos dizer que a concepção de subjetividade na obra herbertiana demonstra-se de modo volátil, plural e, não raro, contraditório. N’A faca não corta o fogo, por exemplo, deparamo-nos com um eu poético que se entusiasma pelo ofício poético: "e quem não queria uma língua dentro da língua?/eu sim queria (...) /que língua,/que húmida, muda, miúda, relativa, absoluta,/e que pouca, incrível, muita," (HELDER, 2009. p. 572-573); e que, ao mesmo tempo, desanima-se diante da impotência criativa que o assola enquanto poeta: "agora não tenho nada defronte,/ não sinto o 
ritmo,/estou separado, inexpugnável, incógnito, pouco,/ninguém me toca,/não toco" (HELDER, 2009, p. 574). Desta maneira, ele alterna-se, apresenta-se, como um eu poético contraditoriamente extático-melancólico.

Num outro aspecto, percebe-se também que a este eu poético se atrela o desejo de ser um poeta obscuro, como podemos verificar em Photomaton \& Vox: "Desejei então ser eu mesmo o mais obscuro dos enigmas vivos, e aplicar as mãos na matéria prima da terra" (HELDER, 1995, p. 12). Este desejo de obscuridade tem mesmo a ver com a concepção herbertiana de uma subjetividade em devir, aquela que sempre morre e renasce em virtude da experiência poética transmutadora - e que, para ser realmente transmutadora, deve exalar obscuridade.

Mudando agora um pouco o nosso foco, e em decorrência do título sugestivo, Retratíssimo on narração de um bomem depois de maio (HELDER, 2009, p. 179-182), analisaremos, a partir daqui, este poema integrante do livro Lugar (1962), no intuito de discorrermos sobre a proposta de uma subjetividade em devir trazida a lume pela obra herbertiana.

Passemos então a comentar sobre alguns versos deste longo e importante poema:

\title{
RETRATÍSSIMO OU NARRAÇÃO DE UM HOMEM DEPO IS DE MAIO
}

\author{
Retratoblíquo sentado. \\ Retratimensamente de/lado, no/acto \\ conceptual de/ver quantos vivos quantos \\ dando folhas sobre os mortos de topázio. \\ Mãosagora, veloz rosto, visão pura. \\ Esquerdo ao/lado, fogo \\ Junto à cabeça. E mais fogo à/direita por/detrás \\ da mão estreita pegando no ar \\ como num livro. Julgo ser eu. \\ Eu às/portas do sono, e não \\ se sabe se venho do sono, oh nem se \\ me empolgo numa ilusão \\ sombria. Eu oh nem se \\ me entro para um sonho extenuante. \\ Sono empurrado de inspiração \\ terrena.
}

O título do poema cria a expectativa no leitor de que o retrato fidelíssimo de alguém será descrito ou apresentado, pois o termo "RETRATÍSSIMO" encontra-se em caixa alta (não só neste poema do livro) e no superlativo. 
Ademais, apresenta-se um diálogo interessante entre fotografia e literatura (ou mais especificamente, a poesia), por se tratar no título de "retrato" ou de "narração". Restanos saber como é este retrato, se dele efetivamente se extrai um rosto bem configurado, entre outros aspectos. Se pensarmos nas possibilidades da fotografia, o retrato que se apreende é uma mera reprodução ou uma criação do real? Há o retrato ou a narração de um sujeito claramente determinado e do qual possamos partir para discorrer sobre a questão da subjetividade?

Passemos ao primeiro verso, "retratoblíquo sentado". Como se trata de um poema do início dos anos 60, notemos que muitas de suas palavras aparecerão aglutinadas ("retrato" + "oblíquo"), justapostas ("mãos" + "agora") ou entremeadas pelo sinal gráfico “/” (para potencializar o sentido de obliquidade?), o que denota alguns rumores da poesia experimental e da poesia concretista em voga naquela época. Deste modo, a palavra "retratoblíquo" configura-se como uma única, resultado da aglutinação de duas outras. E notemos que tal "retratoblíquo" encontra-se "sentado". Provavelmente, trata-se de um "homem" que aparece "sentado" no seu suposto retrato. Em que posição ele se encontra "sentado"? De modo oblíquo, inclinado, ou "retratimensamente de/lado" como bem corrobora o segundo verso do poema.

Além da posição sentada e oblíqua, o homem no retrato encontra-se "no acto". "No acto" de quê, podemos nos indagar? Os dois versos consecutivos respondem que "no acto/conceptual de/ver quantos vivos quantos/ dando folhas sobre os mortos de topázio". Adiantamos, aqui, que este "acto conceptual" refere-se ao ato poético, ou melhor, ao processo criativo do(s) poema(s). Reelaborando então a reflexão acerca dos versos transcritos: quantos poemas herbertianos (os "vivos") surgirão (“dando folhas") deste "acto conceitual" sobre o trabalho do poeta com base na tradição poética ("os mortos de topázio”)?

O "topázio" alude ao material do poema, pois se trata de uma pedra preciosa e amarela. Na poética herbertiana, a cor amarela comumente designa a linguagem poética ou o poema, já que, segundo o conhecimento alquímico, o ouro (amarelo) simboliza o ápice da purificação. Sendo assim, a linguagem poética pode bem ser tida como um trabalho de purificação sobre a linguagem bruta, utilitária e padronizada de nosso dia a dia. Em suma, estes "mortos de topázio" são os valorosos poemas legados pela tradição e que ainda servem de parâmetros para o processo criativo dos poetas atuais. 
O "homem" do retrato é um poeta e os versos seguintes confirmam que ele se encontra em meio ao processo de criação do poema: "Mãosagora, veloz rosto, visão pura./ Esquerdo ao/lado, fogo,/ junto à cabeça. E mais fogo à/direita por/detrás/ da mão estreita pegando no ar/ como num livro. Julgo ser eu". O elemento "fogo" implica o desencadeamento do trabalho poético, disseminador, transmutador e violento, como tal elemento da natureza. Os termos metonímicos "mãosagora", "cabeça" e "mão estreita" ajudam-nos a construir a figura do homem-poeta do retrato. Em seguida, as mãos deste homem pegam no ar "como num livro", o que equipara o processo criativo a uma espécie de ato que estabelece a aproximação entre cultura ("livro") e natureza ("no ar"). Por fim, o eu poético enuncia "Julgo ser eu”, ou seja, a identificação do sujeito consigo mesmo passa ao plano da mera hipótese, já que, na poética herbertiana, o processo criativo sempre transmuta o sujeito para dar lugar a outro renovado. Por isso, falamos da existência de uma subjetividade em devir no âmbito da obra de Herberto Helder.

Logo mais, encontramos "Eu às/portas do sono", trecho que acaba assumindo a plausibilidade do sujeito quando se enuncia o termo "Eu". Este se encontra "nas portas do sono", ou seja, trabalhando o poema. "Sono" que, por sua vez, induz-nos ao "sonho". Quer dizer, trata-se do poeta que trabalha o poema de modo onírico, de modo a associar imagens díspares e distantes da lógica do real e, por isso, Herberto Helder chegou a enunciar em Photomaton \& Vox: "A minha visão confiante é a alucinação" (HELDER, 1995, p. 22).

A seguir, a segunda estrofe do poema continua:

Retratobliquamente livre e martelado em sua leveza.

Com algum espinho meio/visível perto

da cabeça. Como se a cabeça

fosse uma rosa venenosa, ou coisa inclinada e dolorosa. Para ser defendida ou ferida no/acto

da exaltação. Retrato frio. Num grau de ausência, num degrau de alucinação.

Frio nas fronteiras do concreto, e ardente perto perto.

Por/cima, nuvens de cinza revoltada.

Em/baixo, fruta aberta.

Fundos de paisagem veemente e incompleta. 
Agora, a estrofe aponta provavelmente para o processo de transmutação desencadeado em decorrência do processo de criação do poema. O homem do "retrato" (o poeta) confunde-se com a obra (o poema), pois o ato poético torna-os indiscerníveis a ponto de não mais sabermos quem é sujeito e objeto: no "retrato", os trechos do poema "Como se a cabeça/ fosse uma rosa venenosa, ou coisa/inclinada e dolorosa. Para ser defendida/ ou ferida no/acto" acabam por ilustrar a unidade entre o poeta e a obra sendo confeccionada, uma vez que a "cabeça" (do poeta) é comparada a "uma rosa venenosa" (o poema).

O poema é uma máquina que atira para todos os lados, transmutando tudo o que participa de seu processo de confecção: autor e leitor. Nesse sentido, a transmutação implica a morte simbólica do "sujeito anterior" para que outro sempre advenha. Reparemos nos versos "no/acto/ da exaltação. Retrato frio. Num grau/de ausência, num degrau de alucinação" que, por seu turno, indicam o eu poético em xeque, já que seu "retrato frio" encontra-se "num grau/de ausência num degrau de alucinação". Ou seja, este "degrau de alucinação" é o processo criativo do poema que submete o suposto sujeito do retrato a "um grau de ausência", despersonalizando-o.

Analisemos excertos da terceira estrofe:

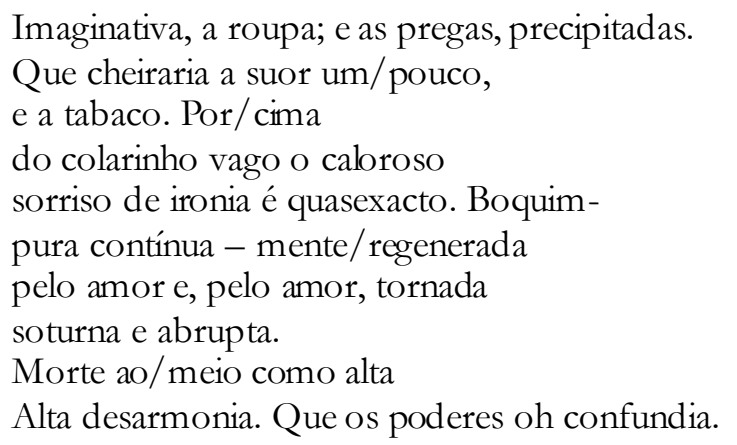

O "retrato" do homem continua a ser narrado a ponto de chegarmos à sua "roupa". Como se trata de um poeta, deparamo-nos com uma "roupa" que cheira a "suor" e a "tabaco", pois o trabalho com as palavras (o "sonho extenuante") molha a roupa do escritor em virtude de seu esforço corporal e o conduz a uma extrema ansiedade, levando-o a fumar compulsivamente inúmeros cigarros.

Adjetiva-se, posteriormente, o "colarinho" da roupa do poeta como "vago". Desta forma, subentendemos que o corpo do homem do "retrato" não o preenche. Indagamo- 
nos: o corpo então se esvaiu? $\mathrm{Na}$ verdade, o tom fantasmagórico da narração refere-se ao completo processo de despersonalização do poeta em razão da confecção do poema, o momento de sua morte simbólica - gradação que vai do trecho "Retrato frio. Num grau/ de ausência" e que culmina no "colarinho vago". O entusiasmo gerado pela produção do poema ("no/acto/da exaltação"), ao mesmo tempo, alterna-se com a sensação de vazio, pois não se sabe o que se perde ou o que se ganha com o processo poético transmutador e, assim, por cima do "colarinho vago" paira o "caloroso sorriso de ironia".

O que se extrai de tudo isso é, enfim, a "mente/regenerada/pelo amor". O processo criativo é um ato amoroso entre o poeta e as palavras e, simultaneamente, um ato purificador, o que implica uma subjetividade em constante movimento. Movimento que não possui outra finalidade a não ser a própria transmutação. A obra herbertiana coloca a tônica no processo criativo - agente da transmutação -, e não no resultado, já que não se pergunta pela utilidade do ato poético.

A seguir, a quarta estrofe:

Ou talvez toda a força se movimente para o centro do retrato.

E a morte se urda do próprio modo como

a carne alimenta o silêncio compacto no/meio do retrato.

Talvez este ser se abisme em seu núcleo central. E toda a figura se levante, na arquitectura da cadeira, por virtude desse nó ou núcleo trágico. Assim como uma pura concepção em/torno de um delírio vingativo e transacto.

Convém ressaltar que esta estrofe do poema se ocupa da reflexão sobre a "natureza" do processo criativo. Obviamente que tal "natureza" não pode ser definida, mas apenas aventada pela palavra poética. Assim, o advérbio de dúvida "talvez" ocorre duas vezes ao leitor do poema para que ele trate qualquer tentativa de descrição do processo criativo como hipótese.

A atenção agora se desloca para o centro do "retrato". Os versos "Ou talvez toda a força se movimente/para o centro do retrato./E a morte se urda do próprio modo como/a carne alimenta o silêncio compacto/no/meio do retrato" configuram o ofício poético como uma atividade centrípeta, isto é, que se volta para si mesma. Como bem escreveu Herberto Helder em Photomaton \& Vox: "A respeito da poesia pode ainda dizer-se: - A 
lâmpada faz com que se veja a própria lâmpada. E também à volta.” (HELDER, 1995, p. 143). Deste modo, o poeta alerta-nos de que a "lâmpada", sobretudo, serve à própria "lâmpada", ou melhor, a poesia deve partir sempre da reflexão sobre a poesia e, por isso, nos versos encontramos os termos "centro do retrato" e "meio do retrato". Aqui, vislumbra-se a impossibilidade da poesia partir das coisas, realizando assim uma espécie de mimese. Para a poética herbertiana, não há realidade a ser referenciada pela poesia, e sim a realidade a ser fundada por ela: a poesia "é um absoluto real" (HELDER, 1995, p. 142).

Consequentemente, não há subjetividade preexistente que sirva de referência para a obra. Ela incessantemente se configura e se reconfigura durante o processo criativo. Quando se escreve que talvez "a morte se urda do próprio modo como/a carne alimenta o silêncio compacto/no/meio do retrato", tem-se a "morte" como a transmutação do eu poético advinda do processo de criação, ou melhor, do poema enquanto construção de "silêncio compacto".

$\mathrm{Na}$ quinta estrofe, encontramos mais elementos a respeito do homem do "retrato":

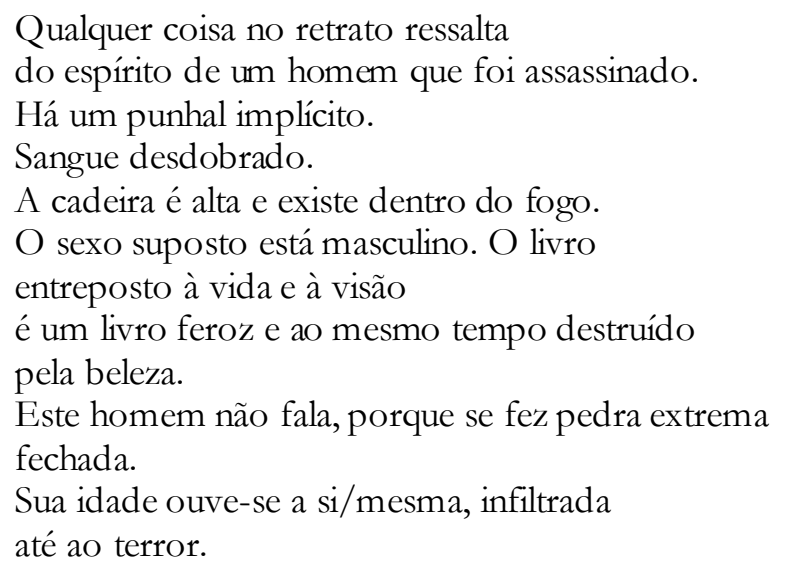

Os versos "Qualquer coisa no retrato ressalta/do espírito de um homem que foi assassinado" novamente suscitam a questão da morte do sujeito do "retrato". Olhando-se para o "retrato", percebe-se algum indício de que o homem da suposta foto "foi assassinado". Os dois próximos versos passam a descrever a cena do "crime": "Há um punhal implícito./Sangue desdobrado". Ou seja, vislumbra-se que o processo de criação do poema, de certo modo, assassinou violentamente o homem do retrato, ou melhor, transmutou-o enquanto eu poético. Trata-se da obra criminosa que sempre põe em xeque a subjetividade em comodidade. 
Como o homem do retrato é, antes de tudo, um poeta, vê-se que "A cadeira é alta e existe dentro do fogo./ O sexo suposto está masculino". Portanto, a "cadeira" no "retrato" é "alta", como a do trono de um rei. Trono de quem possui uma espécie de autoridade. Autoridade: no caso, a autoria do poema. E se ela é "alta" e "existe dentro do fogo", concluímos que o processo transmutador obteve êxito por meio do poema, dado que o "fogo" é elemento da natureza que alude à transmutação. E, finalmente, é interessante notarmos que o verso "O sexo suposto está masculino" coloca em dúvida o próprio gênero daquele que é retratado. Ele "está masculino" e o "sexo" é "suposto". Quer dizer, as coisas mais elementares são postas ao nível de meras hipóteses, o que implica considerarmos o processo criativo realmente um processo de morte, de despersonalização.

Isto se explica também pela própria natureza do processo criativo que, por sua vez, torna precária a distinção entre sujeito (poeta) e obra (objeto), a ponto de configurarem-se como reversíveis e quase indistintos. E, por isso, logo mais adiante se justificam os versos "Este homem não fala, porque se fez pedra extrema/ fechada"; neles, o homem fez-se "pedra extrema fechada", ou melhor, ao confundir-se com a obra (a "pedra") durante o processo poético, não apenas "obrou" o poema, mas "obrou-se", e assim, não manteve a "identidade" anterior. O "homem não fala", já que o processo criativo conduziu-o a uma experiência obscura e transmutadora, que é a do silêncio.

$\mathrm{Na}$ sexta estrofe, mais descrições se seguem acerca do homem do "retrato":

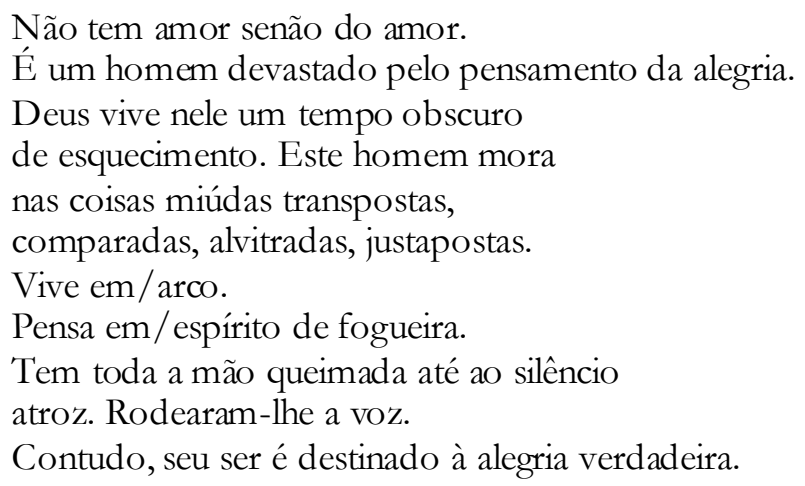

Quem é o homem do "retrato"? Como dissemos, é o "retrato" de um poeta. Ele "mora/nas coisas miúdas transpostas, comparadas, alvitradas, justapostas". Quer dizer, habita nas palavras. No tocante à subjetividade, temos que este homem "Pensa em/espírito de fogueira", pois se trata de uma subjetividade sempre submetida ao crivo da transmutação, da "fogueira". Este homem não para de se transmutar, e melhor seríamos 
imaginá-lo como uma espécie de "retrato" em movimento no papel. Por esta razão, "é um homem devastado pelo pensamento da alegria" e que "tem toda a mão queimada até o silêncio", ou seja, o processo criativo sempre devasta a pretensão de uma subjetividade estável. Queima a mão do homem do "retrato", pois o fogo é indício de transmutação, deixando-o no "silêncio" ou num "tempo obscuro de esquecimento".

A penúltima estrofe do poema afirma que no homem existe "uma assimetria insondável, um destino ou/desatino casto e demorado", corroborando ainda mais que ele se trata de um poeta:

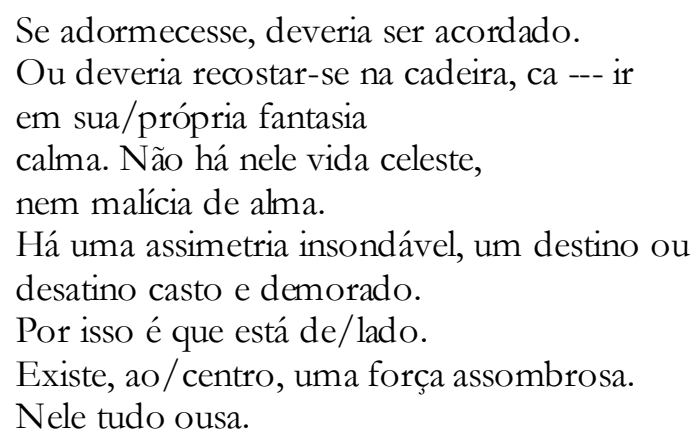

Tal "retrato" aparece "de/lado", visto que o processo criativo não fornece o "retrato" fiel das coisas, mas um perfil fugidio, oblíquo e alusivo. Não fornece "fotos" do real, mas "vultos" de realidade por meio do(s) poema(s), e assim, para a obra herbertiana, tem-se que "A escrita é a aventura de conduzir a realidade até ao enigma, e propor-lhe decifrações problemáticas (enigmáticas)" (HELDER, 1995, p. 145).

Finalmente, deparamo-nos com a última estrofe do poema:

Vai morrer imensamente (ass)assinado.

Por um lado, "assassinado", uma vez que o processo criativo põe em questão qualquer subjetividade que se pretenda assentada, coerente ou estabilizada. O ofício poético é um processo de transmutação, de morte. Sendo assim, o poeta é "assassinado" pela obra e "imensamente" assassinado, já que o ofício poético é uma atividade sem fim e que parece reconduzir o escritor sempre ao ponto de partida. De modo semelhante a um movimento circular, constitui-se notadamente como "passos em volta", pois não há ponto de chegada. Por outro, "assinado" refere-se ao fato da subjetividade ser constituída, configurada pela 
própria obra. Esta o assina, pois continuamente constrói e reconstrói a sua subjetividade, retratando uma subjetividade em devir.

Num dado momento, encontramos em Photomaton \& Vox a seguinte constatação: "somos em todos os instantes quase a nossa morada incerta, estamos sempre à beira de uma indefinida identidade. Encontre-me quem quiser; não vou à procura de ninguém, não vou à minha procura" (HELDER, 1995, p. 163). Esta “indefinida identidade” é a concepção de uma subjetividade em devir, que constantemente morre e renasce, deixandonos incapazes para apreendê-la.

Deste modo, e de acordo com o título do poema, o "retratíssimo" só pode corresponder a uma "narração de um homem depois de maio", na medida em que o "retrato" fidelíssimo deste homem constitui-se unicamente pela narração de seu processo de transmutação ocorrido "depois de maio", depois da estação das flores (depois do poema consumado). E, sobre este incessante e aparentemente módico processo de transmutação ao qual a subjetividade se submete a cada processo criativo, o nosso poeta conclui: 'É alguma coisa, caramba!” (HELDER, 1995, p. 125).

\section{REFERÊNCIAS BIBLIOGRÁFICAS:}

FOUCAULT, Michel. O que é um autor? Trad. J. A. B. Miranda e A. F. Cascais. $4^{\mathrm{a}}$ ed. Lisboa: Passagens, 1997.

HELDER, Herberto. "Lugar". In: Ofício Cantante - poesia completa. Lisboa: Assírio \& Alvim, 2009.

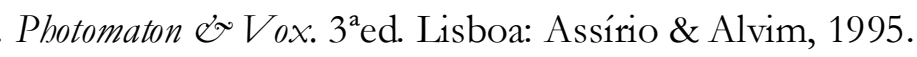
"A faca não corta o fogo". In: Ofício Cantante - poesia completa. Lisboa: Assírio \& Alvim, 2009.

MALLARMÉ, Stéphane. "Crise do verso", tradução de Ana Alencar. Inimigo Rumor, São Paulo, Rio de Janeiro, v. 20, p. 150-164, 2008.

Artigo recebido em 30 de Março de 2012 e aprovado em 6 de Junho de 2012 